[Original Article]

Received July 11, 2017

Revised July 31, 2017

Accepted August 02, 2017

${ }^{\dagger}$ Corresponding author

(mjapark@hanyang.ac.kr)

ORCID

Myoung-Ok Kim

http://orcid.org/0000-0001-5457-7014

Myung-Ja Park

http://orcid.org/0000-0001-8816-0049

\section{Changes in mechanical properties of fusible interlinings on interlock fabrics for T-shirts}

\author{
Myoung-Ok Kim and Myung-Ja Park ${ }^{* \dagger}$
}

Fashion Design Program, School of Design (DAAP), University of Cincinnati, USA Dept. of Clothing and Textiles, Hanyang University, Korea ${ }^{*}$

\section{T-shirt용 환편물의 심지접착에 의한 역학적 특성 변화}

\section{김 명 옥 $\cdot$ 박 명 자 ${ }^{*}$}

Fashion Design Program, School of Design (DAAP), University of Cincinnati, USA 한양대학교 의류학과 ${ }^{*}$

\begin{abstract}
This study aims to analyze the changes in the mechanical properties of interlock fabrics knitted with three types of fibers (i.e., cotton, wool, and polyester) by bonding fusible interlinings with varying deniers (i.e., $10 \mathrm{D}, 20 \mathrm{D}$, and $30 \mathrm{D}$ ) for a $3 \mathrm{D}$ virtual try-on system. We experimented with four properties and thicknesses of twelve specimens of interlining bonded knitted fabrics including face fabrics and interlinings. The results showed that the tensile property changed values (i.e., LT increased, and WT and RT decreased) according to the denier of interlinings; however, the change was slight. On the other hand, the bending property increased significantly as the denier of the interlining increased on both the wale and the course. Among shearing properties, the value of $\mathrm{G}$ increased as the denier of the interlining increased on both the wale and the weft; however, $2 \mathrm{HG}$ decreased. Additionally, changes in the compression property varied according to the fibers and the denier of the interlinings. The thickness of the knitted fabrics increased or decreased slightly by bonding the interlining. based on these results, we conclude that the 3D virtual system users need to reflect these numerical changes of interlock fabrics by bonding interlinings when they perform fitting tasks on the screen to accurately express the to accurately express the manufacturing conditions of the real garment.
\end{abstract}

Keywords: interlock fabric(인터록편성물), mechanical properties(역학적 성질), interlining(심지), denier(데니어)

\section{Introduction}

한국산업의 근대화에 중추적인 역할을 했던 노동집약적인 의류봉제산업은 1990 년대부터 제 3 국가의 저임금을 기반으로 한 해외소싱의 증가로 사양산업이 되었으 며, 과학기술의 발달과 함께 computer aided design 프로그램 기술의 사용이 섬유 패션산업에서 나날이 증가하고 있다. 이러한 기술의 발달은 $\mathrm{CAD}, \mathrm{CAM}$ 에 이어 
$3 \mathrm{D}$ 가상착의까지 발전하였는데, 특히 10 여년 전에 소개된 $3 \mathrm{D}$ 가상착의 시스템은 여러 가지 이점으로 인해 끊임없이 발전하고 있다. 즉, 컴퓨터 스크린을 통하여 직접 눈으로 보면서 디자인과 패턴 수정이 가 능하여 의류제품 개발을 용이하게 하고, 시간을 단축 시키는 가상 피팅이 가능하다. 특히나 컴퓨터에 익숙 한 젊은 세대에게 $3 \mathrm{D}$ 가상착의 시스템 운영 직업은 새로운 직종으로 주목할 만하며, 21세기 눈부신 과학 기술의 발달은 직접 의복을 제작하지 않고도 $3 \mathrm{D}$ 가 상착의를 통하여 패턴과 디자인을 미리 수정하여 의 복의 품질을 향상시키는데 기여하고 있다 $(\mathrm{Kim} \&$ Park, 2013).

현재 $3 \mathrm{D}$ 가상착의 시스템은 상업적으로 의류제품 개발 시 시간과 비용을 줄이는 장점을 가지고 있다. 디자이너가 실제로 의복재료인 천을 재단하기 전에 컴퓨터 스크린에서 의복의 디자인과 피팅을 점검함 으로써, 발생가능성이 있는 문제점을 어느 정도 해결 할 수 있다. 또한 $3 \mathrm{D}$ 가상착의 이미지는 온라인 마켓 에서 소비자가 의류제품을 구매하기 전에 소비자의 신체이미지를 반영한 아바타로 사용이 가능하다. 더 불어 젊은 소비자는 이러한 온라인 시스템을 이용하 여 구매하는 것에 거부감이 없고 선호하여(Kim \& Park, 2014), 이러한 장점으로 인하여 가상착의 시스 템은 향후에도 더 발전할 것으로 기대된다.

국내외적으로 $3 \mathrm{D}$ 가상착의 시스템을 제공하는 대 표적인 프로그램은 Gerber사의 V-Stitcher, OptiTex사 의 3D Runway, Lectra사의 3DFit, 그리고 Virtual Fashion사의 CLO 3D 등이 있다(Lee \& Sohn, 2011). 가 상착의 시스템을 운영하기 위해 $3 \mathrm{D}$ 운영시스템은 기 본적인 물성을 초기값으로 제공하고 있다. 따라서 가 상착의 시스템은 의복이미지를 생성하기 위해 수치 적으로 굽힘특성, 전단특성, 밀도, 두께 등과 같은 역 학적 특성을 필요로 한다(CLO virtual fashion, 2013). 컴퓨터 스크린 상의 의복이미지는 실제 의류제조조 건과 동일한 물성을 반영하여야만 가상착의를 통한 피팅과 디자인 조정이 유효한 작업이 되며, 동일한 물성을 반영하지 못한다면 애니메이션과 같은 이미 지만을 생성하여 가상착의 시스템을 통한 피팅작업 은 의류산업현장에서 적용하기 어렵게 된다.

이와 같이 의류제조현장에서와 동일한 $3 \mathrm{D}$ 의복이 미지를 생성하기 위해서는 의류제조현장의 제작조건
을 반영하여야 한다. 의류제작 시 의복은 아이템과 부위에 따라 다양한 부자재가 사용되며, 대표적인 부 자재는 의복의 형태안정성을 위해 사용되어지는 심 지이다. 의복의 심지는 의복의 외부에서는 보이지 않 지만, 의복의 형태를 좌우하는 의복구성상 매우 중요 한 소재이다(Cho, 1997). 심지를 접착하는 이유는 형 태안정성을 향상시키기 때문으로, 주로 의복의 앞면, 칼라, 밴드, 커프스, 플라켓 등과 같은 곳에 접착한다 (Kang \& Suh, 2007).

그 동안의 선행연구를 살펴보면, Fan and $\mathrm{Ng}(2001)$ 은 polyamide, polyester, rayon의 혼합직물에 부직포 심지를 접착하여 부직포 심지의 객관적 평가에 대한 연구를 하였으며, Seo and Lee(2003)는 심지 접착에 의한 모직물의 굽힙특성 변화에 대한 연구를 하였다. Kim, Inui, and Takatera(2011)는 woven 직물의 심지 접착에 따른 Kanayama's prediction methods를 검증 하고, 굽힘특성의 변화와 예측에 대한 연구를 하였으 며, Choi and $\operatorname{Kim}(2012)$ 은 니트소재의 인장특성과 3D 디지털 클로딩 시스템에 의한 외적 표현에 관한 연구 를 진행하였다. 또한 Kim and Park(2013)은 3D 가상 착의 시스템 사용을 위한 재킷용 면직물의 심지접착 에 의한 물성변화를 연구하였으며, 소재를 달리하여 블라우스용 직물의 심지접착에 의한 역학적 특성변 화 연구를 진행하였다(Kim \& Park, 2014).

이상과 같이 $3 \mathrm{D}$ 가상착의 시스템의 사용이 증가하 고 있는 상황에서 심지 및 심지를 접착한 직물에 대 한 여러 연구가 진행되어 왔으나, 일상생활에서 많이 착용되고 있는 환편물의 심지접착에 의한 역학적 특 성변화에 대한 연구는 미흡한 실정이다. 특히 T-shirt 용으로 주로 사용되는 저지 환편물의 경우는 편직물 의 특성으로 인하여 매우 유연하고 신축성이 매우 뛰 어나다. 그러므로 T-shirt의 디테일로 사용 가능한 밴 드, 커프스, 플라켓 등에 직물심지가 접착되면 이러한 부위의 역학적 특성은 심지가 접착되지 않은 부위와 매우 상이할 것으로 예상되며, 또한 환편물의 섬유종 류와 직물심지의 두께 등도 심지접착포의 특성변화 에 영향을 미칠 것으로 생각된다.

따라서 본 연구에서는 섬유의 종류를 달리한 cotton, wool, polyester 3 종류의 환편물과 직물심지의 두께 $(10 \mathrm{D}, 20 \mathrm{D}, 30 \mathrm{D})$ 를 다르게 선정하여 심지를 접착하 고, 심지접착에 의한 역학적 특성의 변화를 분석해 
보고자 한다. 이를 통하여 T-shirt용 저지 환편물에 데 니어를 달리한 직물심지의 접착에 따른 물성 변화를 알아보아 $3 \mathrm{D}$ 가상착의 시스템 사용을 위한 기초 자 료를 제공하고자 한다.

\section{Methods}

\section{Materials}

연구용 시료는 겉감 환편물과 심지로 나누어 선정 하였다. 환편물은 섬유종류에 따라 cotton, wool, polyester의 3종류를 선정하였으며, Testfabric, Inc(USA) 에서 무게가 유사한(187 205g 범위) 저지(jersey)로 선정하여 구매함으로써 섬유의 특성변화를 비교하고 자 하였다. 각 겉감 환편물의 기본적 특성은 〈Table $1>$ 과 같다. 또한 직물심지의 선정은 환편물 제조업체 와의 인터뷰를 통하여 현재의 심지사용 경향은 얇은 직물심지를 선호한다는 것을 고려하여, 시중에서 가 장 많이 사용되고 있는 심지의 데니어로 10 데니어, 20데니어, 30데니어로 구분하여 3종류를 선정하였다. 심지는 Ilshin, Inc(Korea)에서 상품화되어 판매되고 있는 심지로 구입하였으며, 각 심지의 기본적 특성은 〈Table 2〉와 같다.

\section{Fused materials}

심지 접착은 준비한 3종류의 섬유종류별 저지에 데

$<$ Table 1> Physical properties of face knitted fabrics

\begin{tabular}{c|c|c|c|c}
\hline $\begin{array}{c}\text { Sample } \\
\text { code }\end{array}$ & $\begin{array}{c}\text { Fiber } \\
(\%)\end{array}$ & $\begin{array}{c}\text { Weave } \\
\text { structure }\end{array}$ & $\begin{array}{c}\text { Weight } \\
\left(\mathrm{g} / \mathrm{m}^{2}\right)\end{array}$ & $\begin{array}{c}\text { Thickness } \\
(\mathrm{mm})\end{array}$ \\
\hline $\mathrm{C}$ & Cotton 100 & Interlock & 187 & 1.175 \\
\hline $\mathrm{W}$ & Wool 100 & Interlock & 205 & 1.191 \\
\hline $\mathrm{P}$ & Polyester 100 & Interlock & 200 & 0.91 \\
\hline
\end{tabular}

$<$ Table 3> Sample specification of the combination of face fabrics and interlinings

\begin{tabular}{c|c|c|c|c}
\hline Fiber & $\begin{array}{c}\text { Without } \\
\text { interlining }\end{array}$ & $\begin{array}{c}10 \text { denier } \\
\text { interlining }\end{array}$ & $\begin{array}{c}20 \text { denier } \\
\text { interlining }\end{array}$ & $\begin{array}{c}30 \text { denier } \\
\text { interlining }\end{array}$ \\
\hline Cotton & CI-0 & CI-10 & CI-20 & CI-30 \\
\hline Wool & WI-0 & WI-10 & WI-20 & WI-30 \\
\hline Polyester & PI-0 & PI-10 & PI-20 & PI-30 \\
\hline
\end{tabular}

니어가 다른 3 종류의 심지를 접착하였다. 환편물과 심 지를 각각 원단의 가장자리에서 $10 \mathrm{~cm}$ 이상 떨어진 곳 에서 경사, 위사방향으로 $21 \mathrm{~cm}$ 로 먼저 재단한 이후 심지 접착한 이후 경사, 위사방향으로 $20 \mathrm{~cm}$ 크기로 다시 재단하였다. 심지를 접착하는 방법은 의류제조업 에서 20년 이상 근무한 전문가에게 실제 공정에서와 동일한 조건에서 접착하도록 의뢰하였다. 총 시료는 심지접착 전의 3 종류의 저지와 각각의 저지에 10 데니 어, 20 데니어, 30 데니어의 심지접착 후의 9 종류를 합 하여 총 12 종류의 시료를 준비하였다(Table 3).

\section{Experiment}

준비한 총 12 종류 시료의 역학적 성질은 KES-FBAUTO system(Kawabata Evaluation System for Fabric, Kato Tech. Co. Ltd)을 사용하여〈Table 4〉와 같이 인 장특성, 굽힘특성, 전단특성, 표면특성, 압축특성, 두께 를 측정하였다. 각 시료는 $20 \times 20 \mathrm{~cm}^{2}$ 로 준비하여 표 준계측조건(온도 $20 \pm 1{ }^{\circ} \mathrm{C}$, 습도 $65 \pm 5 \% \mathrm{RH}$ ) 상태에서 24 시간 컨디셔닝한 후, 시료의 다른 부위를 각 3 번 측정하여 평균값을 구하였다.

\section{Results \& Discussions}

\section{Tensile property}

인장특성은 직물에 외부의 힘을 가했을 때 인장되

<Table 2> Physical properties of interlinings

\begin{tabular}{c|c|c|c|c|c|c|c}
\hline $\begin{array}{c}\text { Sample } \\
\text { code }\end{array}$ & Fiber & Denier & $\begin{array}{c}\text { Weight } \\
\left(\mathrm{g} / \mathrm{m}^{2}\right)\end{array}$ & $\begin{array}{c}\text { Thickness } \\
(\mathrm{mm})\end{array}$ & $\begin{array}{c}\text { Dot screen } \\
\text { (holes/inch) }\end{array}$ & $\begin{array}{c}\text { Weave } \\
\text { structure }\end{array}$ & Adhesive \\
\hline I-10 & Polyester 100\% & 10 & 12 & 0.096 & 38 & Plain & Polyamide \\
\hline I-20 & Polyester 100\% & 20 & 23 & 0.155 & 35 & Plain & Polyamide \\
\hline I-30 & Polyester 100\% & 30 & 33 & 0.207 & 30 & Plain & Polyamide \\
\hline
\end{tabular}


<Table 4> Characteristic values of basic mechanical properties with KES-FB

\begin{tabular}{|c|c|c|c|c|}
\hline Mechanical properties & Symbol & Characteristics value & Unit & Apparatus \\
\hline \multirow{4}{*}{ Tensile } & LT & Linearity of load-extension curve & - & \multirow{4}{*}{ KEB-FB1 } \\
\hline & WT & Tensile energy & $\mathrm{gf} \cdot \mathrm{cm} / \mathrm{cm}^{2}$ & \\
\hline & RT & Tensile resilience & $\%$ & \\
\hline & EM & Extension at maximum load & $\%$ & \\
\hline \multirow{2}{*}{ Bending } & $\mathrm{B}$ & Bending rigidity & $\mathrm{gf} \cdot \mathrm{cm}^{2} / \mathrm{cm}$ & \multirow{2}{*}{ KEB-FB2 } \\
\hline & $2 \mathrm{HB}$ & Hysteresis of bending moment & $\mathrm{gf} \cdot \mathrm{cm}^{2} / \mathrm{cm}$ & \\
\hline \multirow{3}{*}{ Shearing } & G & Shear stiffness & $\mathrm{gf} / \mathrm{cm} \cdot \operatorname{deg}$ & \multirow{3}{*}{ KES-FB1 } \\
\hline & $2 \mathrm{HG}$ & Hysteresis of shear force at $0.5 \mathrm{deg}$. of angle & $\mathrm{gf} / \mathrm{cm}$ & \\
\hline & 2HG5 & Hysteresis of shear force at $5 \mathrm{deg}$. of angle & $\mathrm{gf} / \mathrm{cm}$ & \\
\hline \multirow{3}{*}{ Compression } & $\mathrm{LC}$ & Linearity of compression /thickness curve & - & \multirow{3}{*}{ KES-FB3 } \\
\hline & WC & Compressional energy & $\mathrm{gf} \cdot \mathrm{cm} / \mathrm{cm}^{2}$ & \\
\hline & $\mathrm{RC}$ & Compressional resilience & $\%$ & \\
\hline Thickness & $\mathrm{T}$ & Thickness at $0.5 \mathrm{gf} / \mathrm{cm}^{2}$ pressure & $\mathrm{mm}$ & KES-FB3 \\
\hline
\end{tabular}

는 정도 및 회복되는 성질과의 관계이다. 환편물의 심지접착에 따른 인장특성의 변화는 〈Table 5〉와 같다.

인장선형성(LT)은 직물이 신장될 때 강성을 나타내 며, 의복의 구속력 및 압박력과 관계있는 것으로, 값 이 크면 착용감이 떨어지고, 의복의 구속력과 압박력 등의 피로감이 커진다는 것을 의미한다. 전반적으로 심지접착 후 심지는 선형성을 증가시키는 역할을 하 였으며, 데니어가 증가할수록 더욱 증가하는 것으로 나타났다. Wale 방향의 경우, $\operatorname{wool}(1.03 \sim 1.30$ 배)에 대 한 변화가 가장 적었으며, 다음으로 $\operatorname{cotton}(1.25 ~ 1.34$ 배), polyester의 변화(1.56 1.63배)가 가장 많았다. 따 라서 예상할 수 있듯이 직물심지 접착 후 환편물의 강성이 증가함을 알 수 있다.

인장에너지(WT)는 주어진 힘과 신장과의 관계로 서 WT값이 작으면 변형이 쉽지 않고, WT값이 크면 변형이 잘되는 것을 의미한다. 전반적으로 심지접착 후 WT값이 감소하여 환편물이 변형이 쉽지 않음을 알 수 있었다. Wale 방향의 경우, polyester(0.93 0.38배) 이 가장 적게 감소하였으며, cotton(0.86 0.33배), wool (0.56 0.17배) 순으로 많이 감소하였다. Course 방향 의 경우, cotton과 wool은 심지접착으로 인하여 WT 가 현저히 감소하여 형태안정성이 좋아진 것을 확인 하였으며, polyester의 경우 10 과 30 데니어 심지접착
시 WT 값이 다소 증가하여 다른 cotton이나 wool과 는 다른 양상을 나타내어 섬유에 따라 혹은 접착하는 심지의 데니어에 따라 course 방향의 WT는 증가할 수도 있다는 점을 시사하였다. Polyester를 제외한 전 반적인 경향은 접착하는 심지의 데니어가 클수록 $\mathrm{WT}$ 의 값이 감소하여 환편물의 변형이 쉽지 않음을 알 수 있으며, 또한 wale 방향의 WT가 course 방향보 다 영향이 큼을 알 수 있다.

인장회복도(RT)는 인장 후 회복되는 정도로서 값 이 작으면 회복도가 낮고, 값이 크면 회복도가 높아 서 치수안정성이 크다는 것을 의미한다. 심지 접착으 로 인한 변화는 wale 방향의 경우, polyester(1.10 1.29 배)가 가장 적었으며, $\operatorname{wool(1.24~1.46ㅂㅐ),~} \operatorname{cotton}(2.21$ 2.70배) 순으로 나타났다. Polyester와 wool의 변화는 크지 않았으나, cotton의 경우는 2 배 이상 높아진 것 을 알 수 있으며, 심지의 데니어에 따라서 RT 값이 증가하여 cotton 환편물의 치수안정성이 증가함을 알 수 있다. 면직물 심지접착포의 선행연구(Kim \& Park, $2013)$ 결과와 비교해 보면, 면편성물의 경우, 면직물 보다 심지부착 후 인장특성에 대한 영향이 더욱 현저 함을 알 수 있다.

이상과 같이, 심지접착포의 인장특성은 겉감 환편 물의 섬유종류별로 또한 직물심지의 두께별로 그리 
$<$ Table 5> The rate of change of the tensile property of the interlock-interlining bonded fabrics

\begin{tabular}{|c|c|c|c|c|c|c|c|c|c|c|c|c|}
\hline \multirow[b]{2}{*}{ Sample } & \multicolumn{4}{|c|}{$\mathrm{LT}$} & \multicolumn{4}{|c|}{ WT $\left(\mathrm{gf} \cdot \mathrm{cm} / \mathrm{cm}^{2}\right)$} & \multicolumn{4}{|c|}{ RT (\%) } \\
\hline & Wale & $\begin{array}{l}\text { Rate of } \\
\text { change }\end{array}$ & Course & $\begin{array}{l}\text { Rate of } \\
\text { change }\end{array}$ & Wale & $\begin{array}{l}\text { Rate of } \\
\text { change }\end{array}$ & Course & $\begin{array}{l}\text { Rate of } \\
\text { change }\end{array}$ & Wale & $\begin{array}{l}\text { Rate of } \\
\text { change }\end{array}$ & Course & $\begin{array}{l}\text { Rate of } \\
\text { change }\end{array}$ \\
\hline $\mathrm{I}-10$ & 1.44 & - & 1.07 & - & 1.00 & - & 0.85 & - & 5.00 & - & 3.08 & - \\
\hline $\mathrm{I}-20$ & 1.72 & - & 1.06 & - & 1.00 & - & 1.00 & - & 12.30 & - & 7.60 & - \\
\hline $\mathrm{I}-30$ & 1.77 & - & 1.21 & - & 1.00 & - & 1.00 & - & 18.60 & - & 16.35 & - \\
\hline CI-0 & 0.68 & 1.00 & 0.72 & 1.00 & 1.44 & 1.00 & 5.96 & 1.00 & 27.78 & 1.00 & 35.91 & 1.00 \\
\hline CI-10 & 0.85 & 1.25 & 0.91 & 1.26 & 1.24 & 0.86 & 2.24 & 0.38 & 61.29 & 2.21 & 58.04 & 1.62 \\
\hline CI-20 & 0.87 & 1.27 & 0.75 & 1.04 & 0.96 & 0.67 & 2.50 & 0.42 & 66.67 & 2.40 & 64.00 & 1.78 \\
\hline CI-30 & 0.91 & 1.34 & 0.83 & 1.15 & 0.48 & 0.33 & 2.46 & 0.41 & 75.00 & 2.70 & 65.85 & 1.83 \\
\hline WI-0 & 0.75 & 1.00 & 0.79 & 1.00 & 2.88 & 1.00 & 5.40 & 1.00 & 57.64 & 1.00 & 70.00 & 1.00 \\
\hline WI-10 & 0.78 & 1.03 & 0.81 & 1.03 & 1.60 & 0.56 & 2.36 & 0.44 & 71.43 & 1.24 & 65.25 & 0.93 \\
\hline WI-20 & 0.79 & 1.04 & 0.76 & 0.96 & 1.13 & 0.39 & 2.46 & 0.46 & 77.78 & 1.35 & 68.29 & 0.98 \\
\hline WI-30 & 0.98 & 1.30 & 0.85 & 1.07 & 0.50 & 0.17 & 1.96 & 0.36 & 84.00 & 1.46 & 73.47 & 1.05 \\
\hline PI-0 & 0.51 & 1.00 & 0.47 & 1.00 & 1.22 & 1.00 & 1.36 & 1.00 & 63.93 & 1.00 & 41.18 & 1.00 \\
\hline PI-10 & 0.83 & 1.63 & 0.85 & 1.83 & 1.14 & 0.93 & 1.52 & 1.12 & 70.18 & 1.10 & 65.79 & 1.60 \\
\hline PI-20 & 0.79 & 1.56 & 0.81 & 1.74 & 0.98 & 0.80 & 1.16 & 0.85 & 70.31 & 1.10 & 79.25 & 1.92 \\
\hline PI-30 & 0.82 & 1.62 & 0.77 & 1.65 & 0.46 & 0.38 & 1.54 & 1.13 & 82.61 & 1.29 & 70.13 & 1.70 \\
\hline
\end{tabular}

고 시료의 방향에 따라 변화하였으며, 이러한 변화율 은 $3 \mathrm{D}$ 가상착의 시 물성 변화에 참고할 수 있을 것으 로 생각된다. 심지접착은 환편물에 형태안정성을 주 어 의복 외관이 쉽게 변화하지 않게 형태 안정성을 부여한다. 이러한 심지접착으로 인한 인장특성의 변 화를 $3 \mathrm{D}$ 가상착의 시스템 사용자는 인지하여, 특히 심지접착 후 $\mathrm{CI}$ 의 급격한 $\mathrm{RT}$ 증가와 $\mathrm{WI}$ 의 현저한 $\mathrm{WT}$ 감소 경향은 가상착의 프로그램 사용 시 참고하여 기본으로 설정된 초기값이 아닌 보정수치로 환산하여 입력되어야할 것으로 사료된다.

\section{Bending property}

굽힘특성은 직물의 미끄럼 저항, drape성, 유연함, 구김이나 주름과 관련된 형태안정성 성질로 심지접 착에 의한 환편물의 굽힘특성은 〈Table 6〉과 같다.

굽힘강성(B)은 드레이프성과 의복의 형태안정성에 영향을 미치는데, 심지 접착으로 인하여 값이 크게 증가하였으며, 심지의 데니어가 커질수록 비례적으로
증가하였다. Wale 방향의 경우, $\operatorname{cotton}(1.96$ 3.564배), wool (2.75 5.73배), polyester(2.73 8.15배) 순으로 값 이 현저히 증가하였다. 즉, 환편물에 직물심지 접착 시 심지가 두꺼울수록 접착포는 뻣뻣해지고, drape성이 떨어지는 것을 알 수 있다. Cotton과 wool의 경우는 wale 방향보다 course 방향의 변화가 다소 높았으며, polyester는 wale 방향이 course 방향보다 변화가 컸다.

굽힘이력 $(2 \mathrm{HB})$ 의 경우, 환편물에 심지를 접착한 굽 힘이력(2HB)은 굽힘강성(B)과 유사하게 나타났다. 즉, 접착하는 심지가 두꺼울수록 $2 \mathrm{HB}$ 값이 비례로 증가하 여 심지를 접착하기 전보다 직물의 유연함이 떨어지 는 것을 알 수 있었다. Wale 방향의 경우, cotton (1.61 2.34배), wool(3.24 6.88 배), polyester(3.33 8.66배) 순으로 값이 크게 증가하였다. 값의 변화율은 wale 방향의 경우가 course 방향보다 큰 것으로 나타났다.

이상과 같이, 굽힘특성은 wale 방향의 경우, polyester가 심지의 접착으로 인한 값의 증가가 가장 높았 으며, course 방향의 경우는 wool이 가장 높은 것으로 
$<$ Table 6> The rate of change of the bending property of the interlock-interlining bonded fabrics

\begin{tabular}{|c|c|c|c|c|c|c|c|c|}
\hline \multirow{2}{*}{ Sample } & \multicolumn{4}{|c|}{$\mathrm{B}\left(\mathrm{gf} \cdot \mathrm{cm}^{2} / \mathrm{cm}\right)$} & \multicolumn{4}{|c|}{$2 \mathrm{HB}\left(\mathrm{gf} \cdot \mathrm{cm}^{2} / \mathrm{cm}\right)$} \\
\hline & Wale & Rate of change & Course & Rate of change & Wale & Rate of change & Course & Rate of change \\
\hline $\mathrm{I}-10$ & 0.00 & - & 0.00 & - & 0.01 & - & 0.01 & - \\
\hline $\mathrm{I}-20$ & 0.00 & - & 0.00 & - & 0.01 & - & 0.01 & - \\
\hline $\mathrm{I}-30$ & 0.01 & - & 0.01 & - & 0.01 & - & 0.01 & - \\
\hline CI-0 & 0.12 & 1.00 & 0.03 & 1.00 & 0.19 & 1.00 & 0.04 & 1.00 \\
\hline CI-10 & 0.24 & 1.96 & 0.12 & 3.61 & 0.30 & 1.61 & 0.12 & 2.71 \\
\hline CI-20 & 0.38 & 3.09 & 0.15 & 4.59 & 0.37 & 1.98 & 0.13 & 3.08 \\
\hline CI-30 & 0.44 & 3.56 & 0.17 & 4.99 & 0.44 & 2.34 & 0.14 & 3.31 \\
\hline WI-0 & 0.05 & 1.00 & 0.29 & 1.00 & 0.04 & 1.00 & 0.02 & 1.00 \\
\hline WI-10 & 0.14 & 2.75 & 0.12 & 4.03 & 0.12 & 3.24 & 0.08 & 3.77 \\
\hline WI-20 & 0.21 & 4.30 & 0.13 & 4.45 & 0.16 & 4.45 & 0.08 & 3.65 \\
\hline WI-30 & 0.29 & 5.73 & 0.16 & 5.30 & 0.25 & 6.88 & 0.10 & 4.89 \\
\hline PI-0 & 0.06 & 1.00 & 0.06 & 1.00 & 0.05 & 1.00 & 0.04 & 1.00 \\
\hline PI-10 & 0.16 & 2.73 & 0.18 & 2.96 & 0.16 & 3.33 & 0.12 & 3.51 \\
\hline PI-20 & 0.20 & 3.46 & 0.23 & 3.92 & 0.13 & 2.73 & 0.16 & 4.64 \\
\hline PI-30 & 0.47 & 8.15 & 0.24 & 4.09 & 0.42 & 8.66 & 0.15 & 4.16 \\
\hline
\end{tabular}

나타났다. 겉감이 면직물(Kim \& Park, 2013) 혹은 면 편성물 등 조직과 상관없이 심지접착으로 인한 굽힘 특성의 증가는 매우 현저하여 $3 \mathrm{D}$ 가상착의 시스템 사용자는 환편물 의류 봉제 시 심지를 접착하는 의복 의 부위는 이러한 소재 물성의 변화를 반영하여 반드 시 보정 수치로 입력해야할 것으로 판단된다.

\section{Shearing property}

전단특성은 굽힘특성과 관계있는 것으로 인체곡선 과 융화되기 쉽고 동작할 때 인체의 변형에 따르거나 drape성에 영향을 미치는 요소이다. 직물의 심지접착 에 따른 전단특성의 결과는 〈Table 7〉과 같다.

전단강성 $(\mathrm{G})$ 은 값이 크면 의복의 형태안정성이 높 다는 것을 의미한다. 심지 접착으로 인하여 3종류 환 편물의 $\mathrm{G}$ 값이 증가하였으며, 심지의 두께가 높을수 록 값이 높게 나타났다. 이러한 결과는 굽힘특성의 결과와 유사한 것으로 심지접착으로 인해 직물의 변 형이 용이하지 않음을 지지해주는 것을 확인하였다. Wale 방향의 경우, cotton(0.96 1.22배), polyester(1.06
1.53배), wool(1.27 1.98배) 순으로 값이 증가하였다. 값의 변화율은 wale 방향의 경우가 course 방향보다 다소 큰 것으로 나타났다.

전단이력 $(2 \mathrm{HG})$ 은 전단강성에 영향을 받는데, 심지 의 접착으로 인하여 $2 \mathrm{HG}$ 값은 감소하였는데, wale 방 향의 경우, wool(0.71 0.57배), cotton(0.82 0.55배), polyester (0.80 0.50배) 순으로 값이 감소하였다. 이는 선 행연구에서 심지접착포의 겉감이 직물인 경우 전단이 력이 모두 증가하였는데(Jee \& Rue, 1995; Kim \& Park, 2014), 니트겉감의 경우 반대의 결과를 보였다. 유연 하고 형태안정성이 적은 니트에 직물심지를 접착함으 로써 환편물 중 루프의 자유도가 감소하여 심지접착 포의 형태안정성이 우수해짐을 알 수 있다.

이상과 같이, 환편물의 전단특성은 심지의 접착으 로 인하여 전단강성 $(\mathrm{G})$ 은 증가하고, 이와는 대조적으 로 전단이력 $(2 \mathrm{HG})$ 은 감소하는 것을 확인하였다. 이 러한 결과 역시 3D 시스템 사용 시 소재물성의 변화 를 인지하여 심지접착 전 겉감의 물성이 아닌 심지접 착포의 물성 수치로 환산하여 보정된 수치를 입력해 
$<$ Table $7>$ The rate of change of the shear property of the interlock-interlining bonded fabrics

\begin{tabular}{|c|c|c|c|c|c|c|c|c|}
\hline \multirow{2}{*}{ Sample } & \multicolumn{4}{|c|}{$\mathrm{G}(\mathrm{gf} / \mathrm{cm} \cdot \mathrm{deg})$} & \multicolumn{4}{|c|}{$2 \mathrm{HG}(\mathrm{gf} / \mathrm{cm})$} \\
\hline & Wale & Rate of change & Course & Rate of change & Wale & Rate of change & Course & Rate of change \\
\hline $\mathrm{I}-10$ & 0.26 & - & 0.22 & - & 0.10 & - & 0.10 & - \\
\hline $\mathrm{I}-20$ & 0.24 & - & 0.23 & - & 0.20 & - & 0.17 & - \\
\hline $\mathrm{I}-30$ & 0.31 & - & 0.32 & - & 0.30 & - & 0.38 & - \\
\hline $\mathrm{CI}-0$ & 0.55 & 1.00 & 0.47 & 1.00 & 0.55 & 1.00 & 0.85 & 1.00 \\
\hline CI-10 & 0.53 & 0.96 & 0.49 & 1.04 & 0.40 & 0.73 & 0.35 & 0.41 \\
\hline CI-20 & 0.68 & 1.24 & 0.58 & 1.23 & 0.45 & 0.82 & 0.45 & 0.53 \\
\hline CI-30 & 0.67 & 1.22 & 0.59 & 1.26 & 0.30 & 0.55 & 0.55 & 0.65 \\
\hline WI-0 & 0.49 & 1.00 & 0.49 & 1.00 & 0.35 & 1.00 & 0.35 & 1.00 \\
\hline WI-10 & 0.62 & 1.27 & 0.62 & 1.27 & 0.20 & 0.57 & 0.15 & 0.43 \\
\hline WI-20 & 0.73 & 1.49 & 0.65 & 1.33 & 0.25 & 0.71 & 0.15 & 0.43 \\
\hline WI-30 & 0.97 & 1.98 & 0.79 & 1.61 & 0.25 & 0.71 & 0.30 & 0.86 \\
\hline PI-0 & 0.66 & 1.00 & 0.60 & 1.00 & 0.50 & 1.00 & 0.45 & 1.00 \\
\hline PI-10 & 0.70 & 1.06 & 0.64 & 1.07 & 0.40 & 0.80 & 0.35 & 0.78 \\
\hline PI-20 & 0.89 & 1.35 & 0.74 & 1.23 & 0.40 & 0.80 & 0.25 & 0.56 \\
\hline PI-30 & 1.01 & 1.53 & 0.99 & 1.65 & 0.25 & 0.50 & 0.30 & 0.67 \\
\hline
\end{tabular}

야 할 것으로 사료된다.

\section{Compressional property}

압축특성은 직물의 부피감, 섬도, 풍만감과 관련된 성질로 직물의 두께와 상관관계가 있으며, 심지접착 에 따른 직물의 압축특성의 결과는 〈Table 8)과 같다.

압축선형도 $(\mathrm{LC})$ 는 압축에 대한 선형성으로서, 심 지접착으로 인해 LC 값은 미미하게 증가하거나 감소 한 것으로 나타났다. 환편물은 심지를 접착하지 않은 것이 $\mathrm{LC}$ 값이 적어서, 압축이 부드러우며, 심지접착 포의 압축은 좀 더 벗벗하고 용이하지 않음을 알 수 있었다. 이러한 이유는 심지접착 시에 환편물을 고온 고압으로 처리함으로써 섬유간의 기공들이 감소하여 환편물의 부피감이 감소했을 것으로 생각된다. 특히 필라멘트 섬유인 polyester 환편물의 심지접착포의 경 우, 스테이플 섬유인 cotton과 wool보다 약간 높았다. 이는 이미 필라멘트 섬유끼리 기공없이 나란히 정돈 배열되어 더 압축하기가 용이하지 않기 때문으로 판 단된다.
압축에너지 $(\mathrm{WC})$ 값은 값이 낮으면 압축을 위해 적 은 에너지가 필요하다는 것을 의미한다. 심지접착으 로 인하여 $\operatorname{cotton}(0.78 \sim 0.77$ 배)과 wool(0.69 0.55배) 은 $\mathrm{WC}$ 값이 감소한 것으로 나타나서, 심지접착 후 부 피감이 감소함을 알 수 있다. Polyester(1.03 1.17배) 는 반대로 $\mathrm{WC}$ 값이 약간 증가한 것으로 나타났는데, 이러한 현상은 블라우스용 직물의 심지접착(Kim \& Park, 2014)에서의 연구결과와도 동일한 현상임을 알 수 있다.

압축회복도(RC)는 압축의 탄력적인 회복력을 나타 내는 것으로 값이 작으면 회복도가 떨어지며, 값이 크 면 압축에 유연하다는 것을 의미한다. 환편물의 심지 접착으로 인한 $\mathrm{RC}$ 값의 변화는 매우 다양하게 나타났 다. Wool(0.46 0.09배)과 polyester(0.64 0.34배)는 값 이 크게 감소하였으며, 이와는 대조적으로 cotton(1.37 4.31 배)은 값이 크게 증가한 것으로 나타나, 환편물을 구성하고 있는 섬유종류에 영향을 받음을 알 수 있 다. 이는 압축회복도가 낮은 겉감 cotton 환편물에 압 축회복도가 높은 polyester 심지직물을 부착함으로써 
$<$ Table 8> Rate of change of the compression property of the interlock-interlining bonded fabrics

\begin{tabular}{|c|c|c|c|c|c|c|}
\hline Sample & $\mathrm{LC}$ & Rate of change & $\mathrm{WC}\left(\mathrm{gf} \cdot \mathrm{cm} / \mathrm{cm}^{2}\right)$ & Rate of change & $\mathrm{RC}(\%)$ & Rate of change \\
\hline $\mathrm{I}-10$ & 0.60 & - & 0.07 & - & 8.24 & - \\
\hline $\mathrm{I}-20$ & 0.52 & - & 0.07 & - & 21.51 & - \\
\hline $\mathrm{I}-30$ & 0.55 & - & 0.10 & - & 41.07 & - \\
\hline $\mathrm{CI}-0$ & 0.57 & 1.00 & 0.10 & 1.00 & 8.22 & 1.00 \\
\hline CI-10 & 0.61 & 1.06 & 0.08 & 0.77 & 11.27 & 1.37 \\
\hline CI-20 & 0.62 & 1.09 & 0.08 & 0.78 & 28.83 & 3.51 \\
\hline CI-30 & 0.57 & 0.99 & 0.08 & 0.78 & 35.42 & 4.31 \\
\hline WI-0 & 0.62 & 1.00 & 0.12 & 1.00 & 50.93 & 1.00 \\
\hline WI-10 & 0.65 & 1.04 & 0.09 & 0.69 & 23.65 & 0.46 \\
\hline WI-20 & 0.62 & 0.99 & 0.07 & 0.55 & 8.06 & 0.16 \\
\hline WI-30 & 0.69 & 1.10 & 0.07 & 0.55 & 4.38 & 0.09 \\
\hline PI-0 & 0.72 & 1.00 & 0.04 & 1.00 & 27.90 & 1.00 \\
\hline PI-10 & 0.76 & 1.05 & 0.04 & 1.17 & 12.61 & 0.45 \\
\hline PI-20 & 0.74 & 1.04 & 0.04 & 1.06 & 17.74 & 0.64 \\
\hline PI-30 & 0.83 & 1.16 & 0.04 & 1.03 & 9.43 & 0.34 \\
\hline
\end{tabular}

회복도가 증가했을 것으로 사료된다.

이상과 같이, 환편물은 심지 접착으로 인하여 압축 특성의 변화가 매우 큰 것을 알 수 있다. $\mathrm{LC}$ 값은 변 화가 미미하였으나, $\mathrm{WC}$ 값과 $\mathrm{RC}$ 값은 심지접착으로 인한 변화가 매우 컸으며 그 방향 또한 일정하지 않 은 것으로 나타났다. 따라서 $3 \mathrm{D}$ 가상착의 시스템 사 용 시 심지접착에 의한 의복의 부위를 환편물의 종류 에 따라 변화 정도를 정확히 반영하여 기본으로 설정 된 기초값이 아닌 변화된 수치로 보정하여 입력해야 할 것으로 사료된다.

\section{Thickness}

겉감 환편물에 직물심지를 접착한 시료의 두께에 대한 결과는 〈Table 9〉와 같다.

두께에 대한 결과는 겉감의 섬유특성에 따라 감소 하거나 증가하여 상반되게 나타났다. 심지 접착으로 인 하여 두께가 감소한 이유는 잔털이 많은 스테이플 섬 유인 cotton과 wool 환편물은 루프 사이의 공간이 고온 고압의 심지접착 공정으로 인하여 압착되어, $\operatorname{cotton}(0.94$ 0.99 배)과 wool(0.89 0.89배)로 두께가 감소한 반면,
필라멘트 섬유인 polyester(1.08 1.13배) 심지접착포

$<$ Table 9> The rate of change of the thickness of the interlock interlining bonded fabrics

\begin{tabular}{c|c|c}
\hline Sample & Thickness $(\mathrm{mm})$ & Rate of change \\
\hline CI-0 & 1.18 & 1.00 \\
\hline CI-10 & 1.10 & 0.94 \\
\hline CI-20 & 1.15 & 0.98 \\
\hline CI-30 & 1.16 & 0.99 \\
\hline WI-0 & 1.19 & 1.00 \\
\hline WI-10 & 1.06 & 0.89 \\
\hline WI-20 & 1.06 & 0.89 \\
\hline WI-30 & 1.06 & 0.89 \\
\hline PI-0 & 0.91 & 1.00 \\
\hline PI-10 & 0.98 & 1.08 \\
\hline PI-20 & 1.03 & 1.13 \\
\hline PI-30 & 0.99 & 1.08 \\
\hline
\end{tabular}


의 경우, 다소 증가한 것으로 나타났다. 심지 접착으 로 인하여 증가한 두께는 접착하기 전 두께와 심지의 두께를 단순히 더한 수치보다는 약간 감소하였는데, 이러한 이유는 고온고압에서 접착공정 중에 섬유 사 이의 간격이 가까워지고, 또한 심지 중의 접착제가 용해되어 섬유내로 침투하였기 때문인 것으로 생각 된다(Choi \& Kim, 2012).

따라서 $3 \mathrm{D}$ 가상착의 시스템 사용 시에는 심지를 접 착한 부위에는 환편물의 두께를 다르게 반영하여 의 복을 표현하여야 할 것으로 사료된다.

\section{Conclusion}

본 연구는 섬유종류를 달리한 3종류(cotton, wool, polyester)의 겉감 저지(jersey) 환편물에 시판 중인 폴 리에스터 직물심지의 두께를 달리하여 $(10 \mathrm{D}, 20 \mathrm{D}$, $30 \mathrm{D})$ 접착한 심지접착포 시료에 대한 역학적 성질을 $\mathrm{KES}-\mathrm{FB}$ 시스템을 이용하여 측정하였다. T-shirts용 저 지의 심지접착 전후의 역학적 특성 변화를 분석하여, $3 \mathrm{D}$ 가상착의 시스템의 물성데이터 입력시 수치 보정 을 위한 기초자료를 제공하고자 하였다. 연구를 통해 얻은 결과의 요약 및 결론은 다음과 같다.

인장특성은 환편물에 심지접착 후 전반적으로 인장 성형성(LT)값은 증가하였으며, 인장에너지(WT)값은 감소하였고, 인장회복도(RT)값은 감소하였으나, 섬유 의 종류 혹은 wale과 course 방향에 따라 다소 변화가 있었다. 굽힘특성의 결과, 굽힘강성(B)과 굽힘이력(2HB) 모두 심지접착으로 값이 크게 증가하였으며, 심지의 데니어가 높아질수록 비례로 증가하여 심지 접착으 로 인하여 환편물의 형태안정성이 좋아진 것을 확인 하였다. 전단특성의 결과, 전단강성 $(\mathrm{G})$ 은 굽힘특성과 유사하게 심지접착으로 인하여 환편물의 $\mathrm{G}$ 값이 증가 하였으며, 심지의 데니어가 높을수록 값이 높게 나타 났다. 이와는 반대로 전단이력 $(2 \mathrm{HG})$ 은 심지접착으로 값이 감소하였다. 압축특성의 결과, 압축선형도(LC) 는 심지접착으로 값의 변화가 미미하였으며, 압축에 너지(WC)는 스테이플 섬유인 cotton과 wool 접착심 지포의 값은 감소하였으나, 반대로 필라멘트 섬유인 polyester 접착심지포의 값이 증가하였다. 압축회복도 (RC)는 wool과 polyester 심지접착포의 값이 크게 감 소한 반면, cotton 심지접착포의 값은 크게 증가하여
섬유종류별 대조적인 결과를 보였다. 심지접착에 의 한 환편물의 두께 변화 역시 상반되는 결과를 보였다. 스테이플 섬유인 wool과 cotton 접착심지포의 두께는 미세하게 감소한 반면, polyester는 두께가 약간 증가 하였다.

이와 같이, 환편물에 심지접착 전 후로 역학적 특 성에 매우 차이가 나는 것이 확인되었으며, 이는 겉 감 환편물의 섬유종류별, 직물심지의 데니어별, 접착 포의 방향별로 매우 다른 변화의 양상을 보였다. 따 라서 $3 \mathrm{D}$ 가상착의 시스템 사용 시 의복에 심지가 접 착되는 부위는 심지를 부착하기 전 겉감의 역학적 특 성이 아닌 심지접착 후의 역학적 특성 변화를 정확히 반영하여 보정된 수치를 입력해야 한다. 그래야만 제 작된 의복의 실루엣을 시각적으로 가장 유사하게 모 니터링할 수 있다.

이상과 같은 심지접착으로 인한 구체적인 역학적 특성의 변화에 대한 실험 결과 수치는 $3 \mathrm{D}$ 가상착의 시스템의 사용 시 심지접착 부위의 의복을 정확하게 표현하기 위한 유용하고 실질적인 보정수치를 계산 할 수 있는 데이터를 제공하는 데에 본 연구의 의의 가 있다. $3 \mathrm{D}$ 가상착의 시스템 사용자는 본 연구의 구 체적인 결과치를 활용하여 보정수치를 입력함으로써 의복을 실제제작과 좀 더 근접하게 표현할 수 있을 것으로 기대한다.

\section{References}

Cho, C. (1997). A study on fabric adhesive interlining(3), Family and Environment Research, 35 (1), 257-262.

Choi, K. M., \& Kim, J. J. (2012). A study on the tensile deformation characteristics of knits and appearance using 3D digital virtual clothing systems. Journal of Fashion Business, 16(2), 151162. doi:10.12940/jfb.2012.16.2.151

CLO virtual fashion. (2013). Marvelous designer manual version 3.70. Retrieved October 15, 2013, from http://www.clo.co.kr/manual/CLO3D_MD_Manu al_Korean.pdf

Fan, J., \& Ng, Y. N. (2001). Objective evaluation of the hand of nonwoven fusible interlining. Textile 
Research Journal, 71(8), 661-666. doi:10.1177/ 004051750107100802

Jee, J.-W., \& Ryu, H.-S. (1995). Changes of mechanical properties of wool fabrics with fusible interlinings. Journal of the Korean Society of Clothing and Textiles, 19(4), 671-683.

Kang, S. H., \& Suh, M. A. (2002). 의복의 입체구성: 이론 및 실기 [Practical clothing construction] (2nd ed.). Seoul: Gyomoonsa.

Kim, K. O., Inui, S., \& Takatera, M. (2011). Verification of prediction for bending rigidity of woven fabric laminated with interlining by adhesive bonding. Textile Research Journal, 81(6), 598-607. doi:10.1177/0040517510387212

Kim, M.-O., \& Park, M.-J. (2013). Effects of fusible interlinings on mechanical properties and hand of cotton fabrics for jackets. Textile Science and
Engineering, 50(6), 351-358. doi:10.12772/TSE. 2013.50.351

Kim, M.-O., \& Park, M.-J. (2014). Property changes of woven blouse fabrics by bonding fusible interlinings for a 3D virtual try-on system. Fashion \& Textile Research Journal, 16(6), 1008-1016. doi:10.5805/SFTI.2014.16.6.1008

Lee, M. J., \& Sohn, H. S. (2011). A study on the cases of the application of 3D apparel CAD system to the domestic and overseas fashion education. Journal of the Korean Society of Clothing and Textiles, 35(9), 1112-1124. doi:10.5850/JKSCT. 2011.35.9.1112

Seo, M. H., \& Lee, S. Y. (2003). Effect of interlining adhesion on the bending behavior of wool fabrics. Textile Science and Engineering, 40(3), 238-249. 